\title{
“QUEBRANDO COCO PÁ CRIÁ OS FI, VISTI E CALÇÁ": ETNOBOTÂNICA COM MARGARIDA E MARIA NO BICO DO PAPAGAIO, TOCANTINS, BRASIL
}

\author{
"BREAKING BABASSU COCONUT TO RAISE CHILDREN, DRESS AND PUT ON SHOES" \\ ETHNOBOTANY WITH MARGARIDA AND MARIA AT BICO DO PAPAGAIO, \\ TOCANTINS, BRAZIL
}

Marcos Felipe Gonçalves MAIA ${ }^{1 *}$; Baldur Rocha GIOVANNINI²; Rodney Haulien Oliveira VIANA ${ }^{3}$; Gecilane FERREIRA ${ }^{4}$

\begin{abstract}
1 - Mestre em Educação (UFT). Especialista em Educação e Direitos Humanos (UnB). Licenciado em Biologia (UFT). Bacharel em Biblioteconomia (UnB). Pesquisador do Núcleo de Estudos, Pesquisas e Extensão em Sexualidade, Corporalidade e Direitos. Quadra 109 Norte, Avenida NS 15, Campus Universitário da

UFT. *marcosmaia@uft.edu.br; 2 - Licenciado em Biologia (UFT). baldur@tjto.jus.br; 3 - Doutor em Botânica (UFV). Professor do Curso de Ciências Biológicas da Universidade Federal do Tocantins (UFT), campus de Porto Nacional. Professor do Programa de Pós-Graduação Stricto Sensu em Biodiversidade, Ecologia e Conservação (UFT) e Pós-Graduação Stricto Sensu em Ensino de Ciências e Matemática (UFT). rodney@uft.edu.br. 4 - Doutor em Educação em Ciências e Matemática. (UFMT). Professor do curso de Ciências Biológicas da Universidade Federal do Tocantins (UFT), campus de Araguaína, gecilaneferreira@uft.edu.br
\end{abstract}

\section{RESUMO}

Esta pesquisa buscou compreender como duas mulheres quebradeiras de coco do Bico do Papagaio, Tocantins, Brasil, se relacionam com a planta babaçu (Attalea speciosa Mart. ex Spreng) e seus subprodutos. Como fundamentação e ferramentas teórico-metodológicos, foram utilizadas a Fenomenologia, História Oral e Etnobotânica. A entrevista de História Oral Temática perpassou a vida e o trabalho dessas mulheres, bem como os sentidos e significados do babaçu para as mesmas. Compreendeu-se que as relações são complexas perpassando diversas questões: identificação; trabalho; percepção do meio ambiente e seus processos de alterações; conhecimentos e técnicas familiares, tradicionais, locais; socialização e formação na comunidade; baixa escolaridade formal-estatal; partes utilizáveis da planta e seus subprodutos, como óleo, carvão, telhado, cercas, cestos, esteiras; associação política como ressignificação do sentido de ser "quebradeira de coco". Conclui-se reforçando que a etnobotânica possa servir de contato e vivência com outras culturas, outras formas de saberes, em união. PALAVRAS-CHAVE: Babaçu, Etnobiologia, Mulheres, Trabalho rural.

\begin{abstract}
This research sought to understand how two women who are coconut breakers from Bico do Papagaio, Tocantins, Brazil, relate to the babassu plant (Attalea speciosa Mart. ex Spreng) and its by-products. As foundation and theoretical-methodological tools, we used Phenomenology, Oral History and Ethnobotany. The Thematic Oral History interview covered the life, work, as well the meanings of this plant for the two interviewees. It was understood that relations are complex, permeating questions of subjectivity; identification; work; perception of the environment and its processes of change; familiar, traditional, and local knowledge and their techniques; socialization and training in the community; low formal-state schooling; usable parts of the plant and its by-products, such as oil, coal, roof, fences, baskets, mats; political association as a re-signification of the sense of being "coconut breaker". It has to be emphasized that ethnobotany can serve as contact and experience with other cultures, other forms of knowledge, in union.
\end{abstract}

KEYWORDS: Babassu, Ethnobiology, Women, Rural workers.

\section{INTRODUÇÃO}

Conduzimos esta pesquisa com o objetivo de compreender como duas mulheres quebradeiras de coco do Bico do Papagaio, Tocantins, Brasil, se relacionam com a planta babaçu e seus subprodutos. Foram conduzidas duas entrevistas. Ambas foram gravadas; a participação na pesquisa foi voluntária e elas consentiram mediante termo de consentimento livre e esclarecido em conceder suas falas para esta 
pesquisa, que foi conduzida com orientações do Comitê de Ética em Pesquisa com Seres Humanos da Universidade Federal do Tocantins (CEP/UFT).

Araújo Júnior et al (2014) discorrem sobre a História extrativista do babaçu que remonta ao Período Colonial do Brasil. Desde lá essa amêndoa serve de sustento às famílias brasileiras. Após a II Guerra Mundial, o interesse internacional recai sobre essa oleaginosa. Desde os anos 1950 sua exportação in natura aumenta e as famílias locais, extrativistas, são cada vez mais exploradas. Seu auge de produção foi na década de 1980/90 quando chegou a mais de 250.000 toneladas de amêndoas por ano. No entanto, como o fluxo da comercialização era realizado por atravessadores, aumentou-se o ciclo da pobreza. Leis estaduais e federais tentaram equilibrar essa balança, mas o lado fraco desse embate sofreu, mesmo depois do desinteresse mundial pelo produto, onde os embates voltaram a ser internos, com grileiros, grandes produtores de monocultura e agropecuária. Entretanto, o movimento de "quebradeiras de coco" vem construindo uma articulação política que resulta em resistência, tais como a Lei do Babaçu Livre, uma legislação para ajudar na proteção da produção por meio de técnicas tradicionais e de acesso aos babaçuais pelos habitantes locais e ao redor de fazendas (ARAÚJO JÚNIOR et al., 2014). As nossas entrevistadas estão perpassadas por esse cenário.

O babaçu (Attalea speciosa Mart. ex Spreng) ocorre naturalmente no Brasil e Colômbia. Pertence à família Arecaceae, ocorrendo em três gêneros ${ }^{1}$ : Scheelea, Attalea e Orbignya (PROTÁSIO et al., 2014). Ainda segundo esses autores, as árvores das palmeiras de babaçu podem alcançar 20 metros de altura, com possibilidade de produção de 2,2 a 15,6 toneladas de fruto por ha/ano, sendo o potencial brasileiro estimado em 6,8 toneladas por ano. Segundo Mourão et al. (2016), o Estado do Tocantins é o quarto produtor de amêndoas de babaçu no Brasil. Em grande parte, essa produção é realizada por quebradeiras de coco, que são trabalhadoras rurais de extrativismo primário.

No Bico do Papagaio situa-se a Reserva Extrativista Extremo do Norte do Estado do Tocantins (Decreto Federal $\mathrm{n}^{\circ}$ 535, de 20 de maio de 1992), uma área de interesse social para fins ecológicos, sendo um espaço para real uso da população com tradição extrativista (BRASIL, 1992).

A "quebra do coco" é um serviço penoso, realizado majoritariamente por mulheres, exigindo grande esforço físico e acarretando sérios problemas de saúde, tais como dores, problemas de vista, inflamações, miomas, anemias e doenças de pele. Esse diagnóstico, construído por Mourão et al. (2016), indica que as idades das quebradeiras (no feminino mesmo) de coco variam desde a infância até a velhice; a maioria delas não finalizou o ensino fundamental e trabalha há mais de cinquenta anos na profissão.

Com esse cenário, a mobilização das quebradeiras de coco extrapola a necessidade de legislação, sendo necessária a garantia de direitos constitucionais, tais como condições de vida e de trabalho, proteção e preservação do meio ambiente, reconhecimento da atuação, educação, além de outras problemáticas, tais como empobrecimento, conflitos sociais e muitas outras questões que ainda precisam ser levantadas (ARAÚJO JÚNIOR et al., 2014). Tudo isso torna essencial o trabalho com as memórias coletivas (HALBSBACH, 2013) das mulheres quebradeiras de coco.

\section{MATERIAL E MÉTODOS}

Fundamentamos esta pesquisa na Fenomenologia, na História Oral e na Etnobotânica. A Fenomenologia é uma corrente teórica, não necessariamente coesa, onde podem ser identificadas algumas escolas divergentes, mas sempre com o mesmo fio condutor: as experiências dos indivíduos e suas percepções do núcleo central dessas experiências, denominado muitas vezes de "essência". O que mais destacamos dessa abordagem é o respeito pela pessoa com a qual desenvolvemos a pesquisa, sem nunca a considerar um objeto externo ao sujeito cognoscente. Tampouco, uma relação de subordinação ou dicotomização do dualismo sujeito-objeto (MAIA; ROCHA, 2016; MERLEAU-PONTY, 1999).

Nesse sentido, a História oral narra outras versões para além da história positivista (BARROS, 2010). Seu foco não é biográfico (AMADO; FERREIRA, 1998). Por outro lado, nos faz lembrar que por entre estruturas e conjunturas "há pessoas que se movimentam, que opinam, que reagem, que vivem" (ALBERTI, 2004, p. 14). É um reencontro com a humanidade, com o ser, com o indivíduo muitas vezes homogeneizado em dados estatísticos, ditos históricos. É um destacar a substancialidade e subjetividade daqueles que fazem a História, isto é, os seres humanos que dão sentido às suas vivências.

Nessa busca de sentidos, a Etnobotânica é aqui compreendida como um processo científico que estuda as inter-relações entre seres humanos e as plantas. Esta prática de pesquisa é tão antiga quanto a humanidade, mas sua teorização epistemológico-científica é recente (HAMILTON et al., 2003;

${ }^{1}$ Segundo Arecaceae (2019), os gêneros Scheelea spp. e Orbignya spp. foram unificados em Attalea spp. 
OLIVEIRA et al., 2009). Para Hamilton e colaboradores (2003), o termo Etnobotânica foi usado pela primeira vez por John Harshberger em 1896 para se referir a um estudo botânico-arqueológico nos Estados Unidos. Oliveira et al. (2009) também concordam com essa "origem" da Etnobotânica. Desde então, o termo tem se expandido para agregar estudos de cultura moderna a partir de uma visão interdisciplinar.

Entretanto, ressaltam Albuquerque et al. (2016) que muitos estudos etnobotânicos têm sido apenas descritivos, preocupados essencialmente em documentar usos e nomes locais de plantas. Mesmo aqueles trabalhos de cunho medicinal deixam de lado, ou não têm como foco, os interesses da comunidade local, seus objetivos seriam de obter informações para desenvolver um novo medicamento, deixando de lado a preocupação em construir junto com a comunidade local. Por isso, ressalta-se a necessidade da compreensão da formação deste campo do saber não como uma justaposição de palavras (Etnologia + Botânica), mas antes um olhar inter e transdisciplinar para as relações entre humanos e plantas em suas diversas manifestações.

Os estudos etnobotânicos podem versar sobre diversos temas. A título de exemplo, são encontrados estudos etnobotânicos com achados arqueológicos, tais como do povo teotihuacano no México (VÁZQUEZ-ALONSO et al., 2014); Etnobotânica de canções de Castilla y León, na Espanha (HERRERO; CARDAÑO, 2015); plantas medicinais de diversas comunidades, tais como o estudo feito com as comunidades ribeirinhas do município de Manacapuru, no Amazonas (VÁSQUEZ et al., 2014).

Para Oliveira et al. (2009), os estudos etnobotânicos têm um foco de interesse, de maneira decrescente de número de pesquisas nos seguintes campos: plantas medicinais, domesticação e origem da agricultura, arqueobotânica, plantas comestíveis, estudos etnobotânicos em geral, estudos cognitivos, estudos históricos, pesquisas realizadas em mercados/feiras, dentre outros.

Outra temática de interesse da Etnobotânica é o manejo e o desenvolvimento sustentável, ao que Albuquerque et al. (2016) denominam de "Etnobotânica aplicada", sendo esta aplicação direcionada à conservação e ao desenvolvimento sustentável. Ela deve permitir que os conhecimentos, sabedorias e práticas do povo local desempenhem papel importante na descoberta de soluções para os problemas de conservação e desenvolvimento sustentável.

Além desses interesses, a Etnobotânica tem dado importância para as relações de gênero (representações dos papeis de homens e mulheres) nos saberes e nos fazeres populares sobre as plantas. Dessa maneira, a Etnobotânica é entendida como ciência que estuda "as diferentes dimensões da relação de grupos humanos e as plantas", que está perpassada pelas diferenças tanto na forma de saber, como na forma de formar e transmitir os saberes das comunidades entre homens e mulheres de uma maneira hierarquizada ou segregada (VIU et al., 2010, p. 139).

Etnobotânica indígena, de quintais urbanos, de moradores das florestas, do campo ou até mesmo da cidade são temas transdisciplinares de uma etnobotânica em desenvolvimento. Sendo o Tocantins uma região de ecótonos ${ }^{2}$ (SILVA, 2007) há uma biodiversidade importante, bem como diversidade cultural, não somente indígena, mas também quilombolas, trabalhadores e trabalhadoras rurais, quebradeiras de coco.

O território hoje ocupado pelo Estado do Tocantins já fora pertencente ao Estado de Goiás. A delimitação desse novo Estado se deu com a Constituição Federal de 1988. Entretanto, seu movimento separatista teve início ainda no período colonial brasileiro (1500-1822). Sua fundação se deu em $1^{\circ}$ de janeiro de 1989. Este Estado está situado na região Norte do Brasil, possui 139 municípios e tem a cidade de Palmas como sua capital. Apesar de estar na Amazônia Legal, sua vegetação dominante é o Cerrado. Possui dois grandes rios: o Araguaia e o Tocantins. Seu clima é predominantemente tropical com duas estações bem demarcadas: a seca e a chuvosa (NASCIMENTO, 2011). Sua população é diversa, com migrantes de todo Brasil e do mundo, bem como de comunidades tradicionais, tais como indígenas, quilombolas e quebradeiras de coco.

A figura 1 mostra a distribuição das florestas de babaçu pelo Brasil. Com exceção da Região $\mathrm{Sul}$, todas as outras quatro regiões do Brasil possuem, ao menos, uma pequena parcela de babaçu (PORRO et al., 2011), sendo sua maior concentração no eixo Norte-Nordeste (PROTÁSIO et al., 2014).

\footnotetext{
${ }^{2}$ De acordo com Silva (2007) é justamente nesses espaços de ecótonos onde se pode observar o avanço ou retração de um bioma. No caso do Tocantins, o ecótono Amazônia-Cerrado está no arco do desmatamento, na fronteira agropecuária e madeireira; sendo $60 \%$ da área desse ecótono já desmatadas.
} 


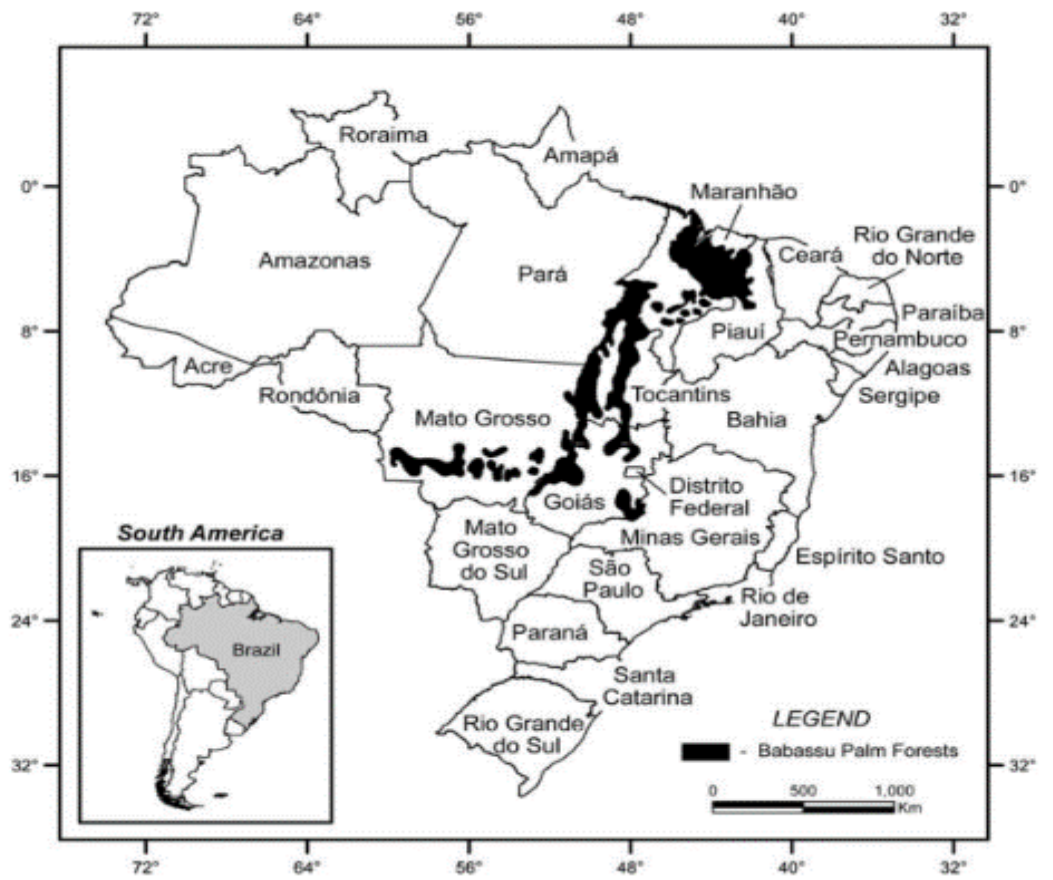

Figura 1: mapa da distribuição do babaçu no Brasil. Fonte: Porro et al. (2011).

Fomos à Chácara São Francisco no povoado Altamira, município de Sítio Novo do Tocantins (figura 2), onde conhecemos a senhora Margarida Ciliana Pereira, uma pessoa amável e receptiva, que nos mostrou suas habilidades e toda a técnica recebida de seus antepassados de como extrair o azeite do coco de babaçu, e tantos outros conhecimentos.

Posteriormente, visitamos a senhora Maria Amorim Silva que mora atualmente em uma casa com uma chácara no fundo, bem no centro do município de Sítio Novo do Tocantins, que nos impressionou com sua simplicidade e habilidade em extrair o azeite de babaçu, e nos demonstrou como este coco pode produzir tantos produtos, como do "olho" (palha) do babaçu se extraem tantos tipos de cofos (cestos) de tamanhos e formas diferentes.

Essas duas mulheres, juntas, possuem quase cem anos de experiências na quebra do coco, por isso somente foram entrevistadas. Além disso, a pesquisa etnobotânica trabalha com pequenos números de entrevistados quando o enfoque é qualitativo (KOGEYAMA, 2018), o que não é uma condição sine qua non, mas interessante quando o enfoque é pela História Oral de vida, ao invés de temática; o que é uma escolha teórica.
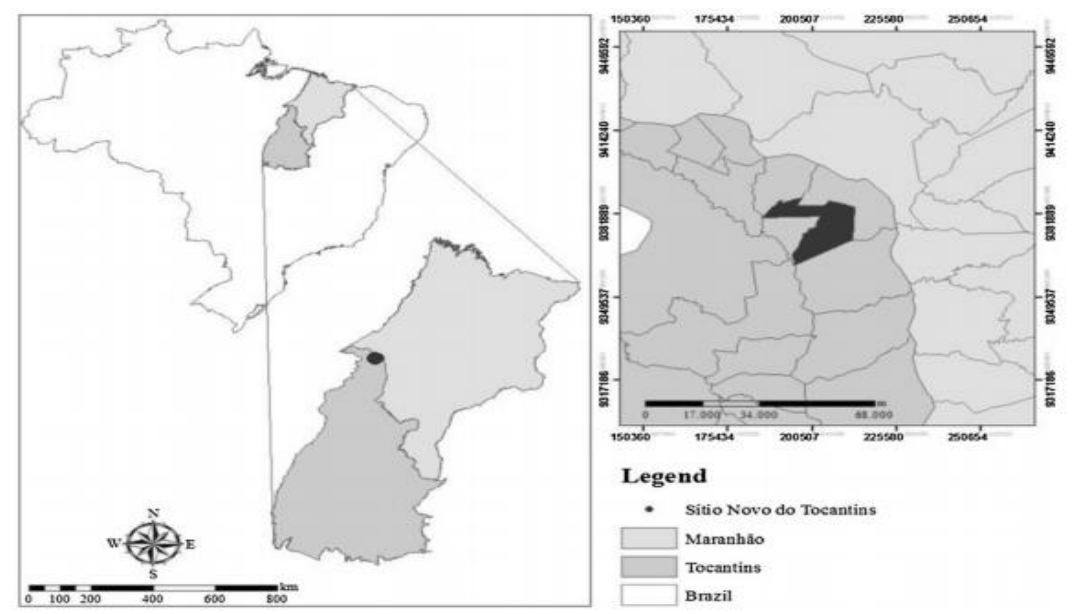

Figura 2: Representação cartográfica da localização do município de Sítio Novo do Tocantins, Brasil, perto da divisa com o Estado do Maranhão. Fonte: Protásio et al. (2014).

\section{RESULTADOS E DISCUSSÃO}

Na perspectiva teórica aqui abordada, as falas e os nomes são o ponto chave. Por isso, os nomes e falas das duas entrevistadas aparecem evidentes já no título deste trabalho. Margarida Ciliana 
Pereira nasceu em 1942. Frequentou poucos anos de escola, mas afirma não ter aprendido nada, "nada mermo". Teve treze filhos, todos já "caíram fora daqui", morando atualmente com dois filhos. Maria Amorim Silva nasceu em 1938, no Maranhão. Não estudou: "Meus pais só me botaram pra i trabaiá". Mora com três filhos. A figura 3 traz imagens dessas duas mulheres quebradeiras de coco.

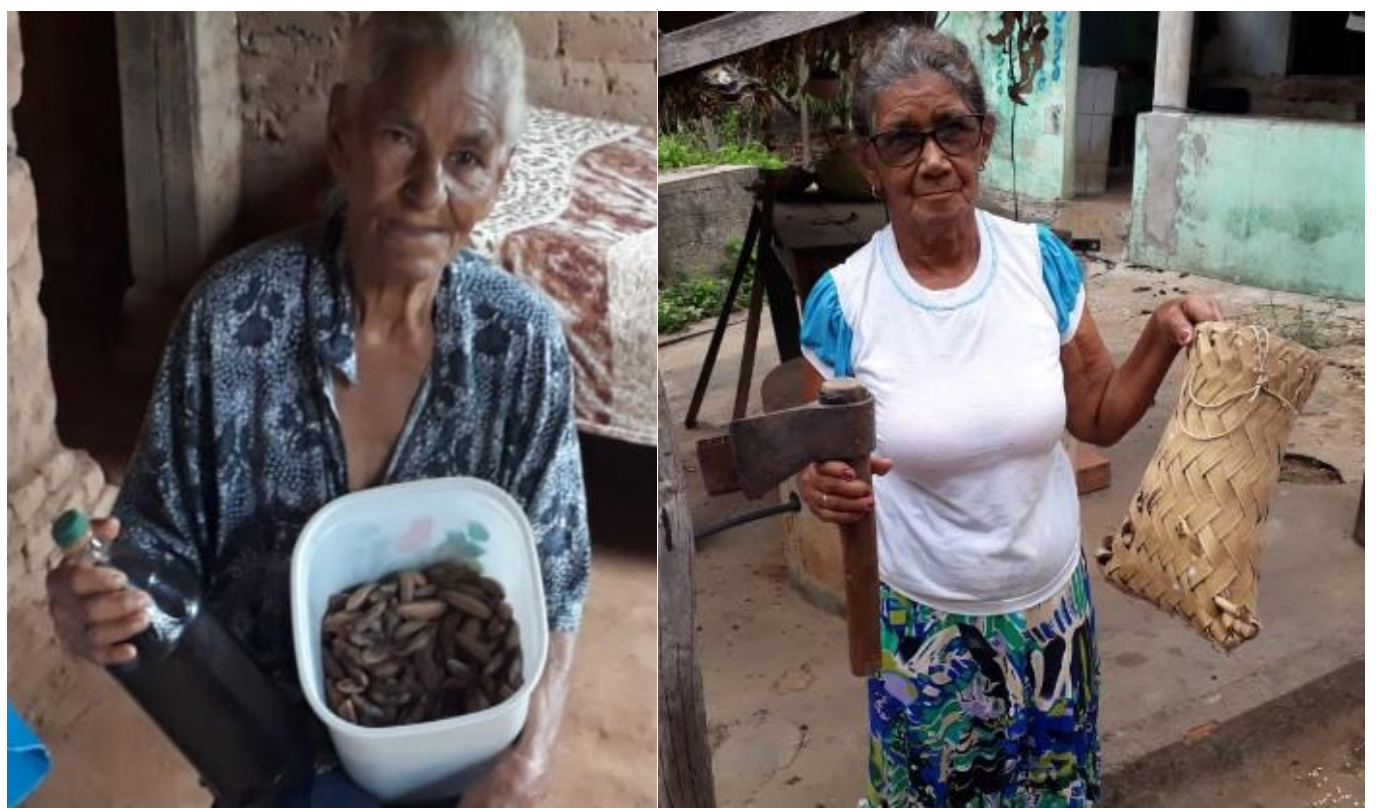

Figura 3: Margarida (à esquerda) e Maria (à direita), quebradeiras de coco entrevistadas para esta pesquisa. Fonte: dos autores.

Ambas se reconhecem como "quebradeiras de coco". Expressão que ganhou uma identidade política para ressignificar o tom estereotipado e preconceituoso que era utilizado por volta dos anos 1950, quando a alcunha significava muito mais um não-local do que um trabalho, profissão (PORRO; et al., 2011). Tanto Margarida quanto Maria viveram esse período. Quando perguntadas sobre o que significa ser "quebradeira de coco", elas respondem:

"Assim, a gente ajunta os coco quebra meio ispaiado, a gente entra na mata e quebra, ai quando num quer ajunta e quebra num lugar só, eu sempre tô ajuntando e quebrando alí, entra na mata junta os coco, quebra o coco [...]" (Margarida Ciliana Pereira).

"Eu criei meus fi tudo quebrando coco e aí o mei de vida meu era só trabaiá num sabe?! Aí casei, parei de trabaiá já de roça e findei toda vida naquele lugar. Quebradeira de coco é um negócio que é só pa gente viver mermo, purque não tem outo mêi de viver aí eu quebrava. Agora eu [...] Deus já deu o meu mêin, já tô véia do jeito que tô, eu dô ur meu mei de viver, que eu sou aposentada mermu e pronto" (Maria Amorim Silva).

Podemos perceber em suas falas que ser "quebradeira de coco" é um trabalho, uma fonte de renda. Mas não é só isso que suas falas demonstram. A subjetividade pode ser produzida por processos de agenciamento de enunciações na relação extra-individual (sistemas econômicos, ecológicos, sociais de mídia, ou seja, sistemas que não são imediatamente humanos) com a infrapessoal (percepção, sensibilidade, afeto, desejo, sistemas corporais, biológicos) (GUATTARI; ROLNIK, 2005). Segundo Guattari e Rolnik (2005), podemos perceber que os processos que as levam a se considerarem "quebradeiras de coco" não é simplesmente uma "escolha", mas uma intrincada relação com questões internas e externas a elas. Veremos mais à frente como o movimento de mulheres agrupadas em associações políticas conseguiram transformar a visão que se tinha estereotipada da expressão "quebradeira de coco", até chegar neste tempo histórico em que mesmo sendo um trabalho difícil, exaustivo (MOURÃO et al., 2016), não gratificante, elas ainda consigam se autodenominarem Quebradeiras de Coco.

Nesse contato com o trabalho totalmente contextualizado pelo meio ambiente, pela natureza e também por questões políticas, elas demonstram uma determinada percepção do ambiente: 
"O coco babaçu é nativo, é nativo, ele cresce por conta. Quando a gente veio pra cá [...] era tudo cheio só de coco... tem muito lugar que os donos das fazenda derrubou, mas adonde os dono não derrubou tem, aqui nóis tem que foi argum pé que foi saltiado, assim num deixô argum pé só pra fazer a roça [...] " (Margarida Ciliana Pereira).

Melhor época do ano pra trabalhar: "É Quase todo tempo. quando a gente pode quebrar, tendo e a corage dando num tendo, tendo precisão a gente pode quebrar, no inverno é mais fraco, agora no verão é mió pra gente quebrar, porque é tudo inchutin, caí a gente ajunta ou vai mermu lápra dibaxo dos pé passsa o caçete, não está chovendo, o coco cai da palmeira, a gente ajunta, vai para baixo do pé e junta os cocos" (Margarida Ciliana Pereira).

"O coco é nativo [...] Ave Maria antigamente a gente vivia era a custa do babaçu [...] Hoje é porque tem muita coisa que graças a Deus a coisa amiôrô né?[...] tô apusentada [...] Aí purissu eu já deixei mais, [...] antigamente [...] era mais importante para ela]." (Maria Amorim Silva).

A percepção para Merleau-Ponty (1999) é um dos fundamentos do saber das coisas; saber tradicional/local ou científico. Quando Margarida percebe que antes tinha mais coco, ela automaticamente dá uma pista do por que dessa mudança, a devastação, que, segundo Novaes e Araújo (2016), são a realidade dessas florestas de babaçu que têm sido destruídas em nome de grandes conglomerados comerciais e agroexportadores. Por outro lado, Maria Amorim se percebe como fora desse contexto por não mais trabalhar quebrando o coco, sendo aposentada, mas mesmo assim traz a percepção de que o coco é nativo, um aprendizado profundo que leva para a vida.

Fica evidente, também, na fala de Margarida que a devastação promovida por acordos empresariais (NOVAES; ARAÚJO, 2016), dos donos das fazendas, já modifica a paisagem. O que para Novaes e Araújo (2016, p. 182) têm limitado "cada vez mais o acesso aos recursos naturais ainda disponíveis".

Com essas e outras percepções, elas começam a construir seus conhecimentos para a vida do trabalho com o coco babaçu. Cada uma, com sua individualidade e processos de subjetivação (GUATTARI; ROLNIK, 2005), aprenderam no seio da comunidade como trabalhar com o babaçu:

"Todo mundo fazia eu comecei dur mai véi e comecei vendo ur mai véi fazendo e eu aprendi também. Minha mãe fazia, os vizinhos fazia, tudo fazia isso, ninguém num fazia, não tinha outo mêi assim pra arrumar dinheiro não, era quebrando coco pá [...] pá vender pra comprar coisa pra vesti, calçar, de vez que até o di cumer mermu a gente fazia isso [...] eu merma vim prá cá mais o meu marido nóis era novin aí começemu a produção aqui nesse mêin aí depois viêmu pra cá era ele na roça e eu coco [...] Quebrando coco pá criar os fi, visti e calçá e ele era pra dá o di cumer, o arroz, fava, feijão tudo [...] agora tá com treis anu que ele morreu, já vivia duente ja muito tempo aí intêrô treis anu agora que ele morreu [...] " (Margarida Ciliana Pereira).

"Eu aprendi a quebrar coco eu era piquinininha a minha mãe levava tudo quanto era de fi que meu pai era alejado aí minha mãe era ai trabaiava pa criar nóis, aí ela ficava era dia na roça cus coco aí chegava lá ela tirava aquelas taiada dos coco e mandava a gente muer cana no braço [...] Minha mãe era quem quebrava assim e dava pa nóis quebrar tirar os bagos. Era quebrar coco antigamente o povo num tinha outo mêi de viver era tudo de roça e quebrando coco, vindia o coco pá comprar alguma coisa." (Maria Amorim Silva).

Essa forma de aprendizado em comunidade, onde os mais velhos ensinam os mais novos, é uma forma tradicional de socialização de um conhecimento desenvolvido por dada comunidade. Esse processo é muitas vezes compreendido como socialização, ou Educação, em sentido lato (MANACORDA, 2006). Essa forma de saber pode, em conjunto com a Ciência formal, ajudar na conservação e boa utilização da natureza: 
[...] as comunidades que utilizam determinado recurso vegetal já possuem inúmeros saberes acerca dos ciclos da planta em questão, bem como dos aspectos que beneficiam ou desfavorecem a ocorrência de populações da espécie. Estes saberes são oriundos de experiências práticas através da vivência nos ecossistemas e podem complementar o conhecimento científico sobre o manejo de populações naturais (BALDAUF et al., 2007, p. 824).

Desse aprendizado, de tempos imemoriais, desde a infância, elas também aprenderam o nome da planta com a qual trabalham. Os nomes e alcunhas dadas às plantas também são de interesse para a Etnobotânica (ALBUQUERQUE et al., 2016). Porro et al. (2011) indicam dois nomes possíveis para o babaçu: Attalea speciosa, ou Orbignya phalerata, enquanto Protásio et al. (2014) indicam três gêneros: Scheelea, Attalea e Orbignya; por outro lado, nossas entrevistadas o denominam de babaçu, coco, palmeira e coqueiro:

"Só conheço como babaçu mesmo, coco, babaçu [...]” (Margarida Ciliana Pereira).

"Quando eu me intendi já eu via chamar era palmeira, era o coqueiro, coqueiro é aquele bem altão que chama [...]. E a palmeira é aquela parte e vão subindo pra dá cacho, vai crescendo é a palmeira, cumeça a dar o cacho de palmeira aí ardispôis ela dá um coqueirao alto [...]" (Maria Amorim Silva).

Os nomes da localidade/comunidade para determinada planta, a partir de uma perspectiva antropológica, geralmente se refere ao processo de experiência ${ }^{3}$ daquela comunidade com a planta (ALBUQUERQUE et al., 2016). Estes mesmos autores chegam à conclusão de que os nomes dados às plantas, ou animais, geralmente seguem uma regra hierárquica próxima da taxonomia científica. Entretanto, o modelo teórico-tradicional-local de compreensão dessas hierarquizações não é necessariamente homogêneo ou eurocentrado (ODA, 2018).

Assim como a experiências das quebradeiras de coco com a natureza são diversas, as finalidades de utilização do coco babaçu variam: Margarida produz carvão, adubo, óleo e estruturas de abrigo e moradia; já Maria produz óleo, sabão, adubo, moradia (faz ressalva quanto ao perigo de fogo destruir a casa), cestos e esteiras (Figura 4).

Partes utilizáveis: "Eu acho que é quase tudo. Porque a madeira mermo a gente faz até chiqueiro pra prender um bicho, a paia, ó ai ó [apontando para a casa], é tapada de paia". Carvão: "A gente cava um buraco no chão, ou então dentu de uns latrão que tem alí ó, uns latrão desse tamanho, a gente ienche e quando bota fogo e quando sobe a gente tampa, aí no ôrtru dia a gente tira aí o carivão tá pronto [...] [Com esse carvão] a gente faz de cumer, a gente quando num tem o gáis aí cuzinha no fogão de barro aí põe enche de carivão e conzinha o di cumer, quando num quer na lenha e aqui faiz tempo que eu nunca mais conzinhei na lenha não, só no fogão mermu, no carivão e no gais". Adubo: "Aqueles pé que cái que apudrece a gente pega e faz o adubo [...] Coloca no canteiro quando tá só o pó. A gente pega e joga no canteiro [...] Do jeito que tá, botalá mistura com a terra lá e faz o plantio [...] É, aquele que tá só o bagaço já [...]”" (Margarida Ciliana Pereira).

“A gente quebrava o coco pá tirar o azeite [...] Dá um bucado de tora de sabão [...] dá uns oito quilos [...]". O adubo "é bom quando ele apudrece aquele coqueirao aquela palmeirona é boa pra gente tirar aquele adubo dele pa botar em cantero [...] A gente pega ele lá onde tá podre véi aí pode chegar e botar no canteiro que tá bom, dá beleza, as fôia as verduras. Só faiz chegar de lá e dispejar irriba porque os zôuto istrumi de gado é obrigado a gente botar de môi pra sair aquele urina do gado, maisi o coquero não, pode panhar e botar. Moradia: "Pode construir casa só que é perigoso o fogo. Que se cair uma faísca irriba aí caba contudo [...]". Artesanato: "Ah côfo [um tipo de cesto] o meu marido

\footnotetext{
${ }^{3}$ Uma experiência curiosa é a assinatura de Paracelso. Paracelso, médico e alquimista suíço do séc. XV, percebeu que algumas comunidades na Índia, África e, depois se descobriu que também em nações indígenas das Américas, costumavam dar utilidade para uma planta de acordo com o seu formato em mímeses com o corpo humano. Por exemplo, plantas com formatos fálicos ou vaginais eram associados à fertilidade ou tratamentos daqueles órgãos miméticos (RODRIGUES; CARLINI, 2005).
} 
fazia ó [...] Ele tirava o olho do babaçu do côco aí ele butava pá muchar e distalava aquele oi de paia ao fazia um côfo, isteira [...] g gente faiz uma côfa pá galinha botar dentro [...] e a cubertura de casa pode arrudiar a casa de paia de coco [...] É pois é as parede, a gente arrudeia de paia [...]” (Maria Amorim Silva).

As utilizações da planta e suas partes são de real interesse para a etnobotânica (OLIVEIRA et al., 2009). Em um estudo sobre a diversidade de palmeiras no território indígena Krahô do Tocantins, Nascimento et al. (2009) encontraram 17 espécies e 10 gêneros com uma infinidade de usos: desde alimentação, passando por construção, uso medicinal, artesanato, utensílios domésticos e rituais; sendo que bacaba (Oenocarpus distichus Mart.) e o buriti (Mauritia flexuosa L.) apresentaram maior diversidade de uso.

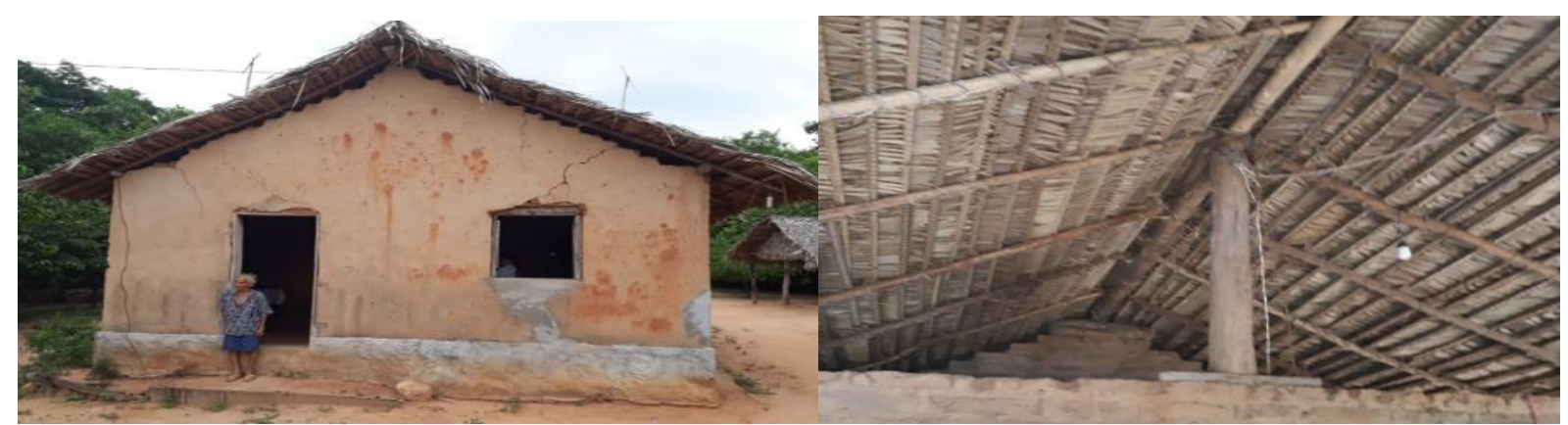

Figura 4: Casa de Margarida feita com adobe com cobertura de palha de coco babaçu. À direita foto interna da cobertura da casa. Fonte: dos autores.

Nesse processo de trabalho de camponesas, trabalhadoras do campo, novos movimentos sociais têm ganhado força. A própria ressignificação da expressão "quebradeira de coco" ganha um novo sentido com o movimento de mulheres quebradeiras de coco já no ano de 1991, quando 240 quebradeiras de coco se juntam em um evento nacional no Maranhão em busca de participação do cenário de representação política (PORRO et al., 2011). Nossas interlocutoras falaram um pouco dessa participação coletiva em associações:

"Eu faço [parte de uma], eu paguei munto aí mar num arrumei a casa não, era com uma muié que tinha aí no cento, ela inganô a gente um bucado, foi munta gente que ela inganô. Assim, ela dizia que ia arrumar, ia mandar fazer a casa das quebradeiras de coco e pegava nosso 5 real todo mêis" (Margarida Ciliana Pereira).

"Associação assim [...] Não [...] aqui agora vejo dizer que já tem num argun lugar assim na Sumaúma, ar Muié já tão quebrando côco tirando o óleo e levando pa Iperatriz [...]” (Maria Amorim Silva).

Para Margarida a experiência de associação não foi muito interessante, enquanto Maria nunca participou de nenhuma, mas ficou sabendo que existe numa cidade vizinha, que acaba ajudando as mulheres a escoarem a produção.

Após aquele evento nacional em 1991, surgiu a Associação do Movimento Interestadual de Quebradeiras de Coco Babaçu - MIQCB. O sexto encontro dessa organização se deu em 2009, em São Luís do Maranhão (PORRO et al., 2011). No mesmo ano em que Raimunda Gomes da Silva, a Dona Raimunda Quebradeira de Coco, recebeu o título de Doutora Honoris Causa pela Universidade Federal do Tocantins - UFT.

Porro et al. (2011) afirmam que como "novo movimento social" o foco do MIQCB não é fazer uma revolução social, mas antes uma reorganização entre economia, estado e sociedade de uma maneira mais democrática e transparente possível. Além das questões de terra e produtividade, esse movimento busca reafirmação de identidade e desconstrução de discursos sobre as "quebradeiras de coco". A emergência desse movimento se baseia numa ideia alternativa de desenvolvimento de suas comunidades nos territórios delineados pelo uso das florestas de babaçu de acordo com suas tradições (PORRO et al., 2011). 


\section{CONCLUSÕES}

Quisemos apresentar um recorte, uma interpretação da fala de duas mulheres Quebradeiras de Coco do povoado Bico do Papagaio, Tocantins. Seus conhecimentos são apresentados numa linguagem delas, com palavras próprias, inclusive.

Margarida Ciliana Pereira. Maria Amorim Silva. Duas senhoras octogenárias. Lúcidas. Com memórias do trabalho, da família, da roça. Duas mulheres com pouca escolaridade e muita responsabilidade de criar famílias. Destinatárias de um processo de usurpação da terra, da mão de obra barata, do empobrecimento.

Duas mulheres que viveram o período de transição do sentido pejorativo de "quebradeiras de coco", para um sentido político, ético, da responsabilidade com o meio ambiente e em favorecimento dos seus conhecimentos, técnicas, tradições e propriedades intelectuais. Com esse cenário, vimos Margarida e Maria. Duas mulheres trabalhadoras do campo.

Identificamos uma diversidade de usos da planta em análise, bem como de significados distintos. Para as duas mulheres aqui entrevistadas, ser "Quebradeira de Coco" é mais do que uma profissão, é um sentido de existir. Elas demonstram percepção de alteração do ambiente e da importância do trabalho em suas vidas e de suas famílias. Destacam também as dificuldades e os sofrimentos vividos nesse processo de trabalho de mais de cinco décadas quebrando coco para criar os filhos, vestir, construir moradias e se alimentar.

Para futuras pesquisas, pensamos em trabalhar mais questões que lhes afetam diretamente, como saúde, moradia e renda. Numa outra abordagem, tentar compreender as potencialidades didáticocurriculares da etnobotânica, e talvez também das etnociências, no ensino de Biologia. Talvez uma maneira de aproximar escola e comunidade, transformar a formação para o trabalho, a cidadania.

Além disso, compreendemos que a Etnobotânica nas suas aproximações com a comunidade deve ser de soma, nunca de subtração. Os saberes devem se encontrar e se transformar para o bem de todos e todas.

\section{REFERÊNCIAS}

ALBERTI, V. Ouvir contar: textos em história oral. Rio de Janeiro: Editora FGV, 2004.

ALBUQUERQUE, U. et al. (Org.). Introduction to Ethnobiology. New York; London: Springer, 2016.

AMADO, J.; FERREIRA, M. (Orgs.). Usos e abusos da história oral. Rio de Janeiro: FGV, 1998.

ARAÚJO JÚNIOR, M. et al. A lei do babaçu livre: uma estratégia para a regulamentação... Sequência, Florianópolis, n. 68, p. 129-157, jun. 2014. Disponível em: < http://dx.doi.org/10.5007/21777055.2013v35n68p129. >. Acesso em 05 fev. 2019.

ARECACEAE. In: Flora do Brasil 2020 em construção. Jardim Botânico do Rio de Janeiro. Disponível em: < http://reflora.jbrj.gov.br/reflora/floradobrasil/FB15675 >. Acesso em 16 fev. 2019.

BALDAUF, C. et al. Caracterização etnobotânica dos sistemas de manejo de samambaia-preta (Rumohra adiantiformis (G. Forst) Ching - Dryopteridaceae) utilizados no sul do Brasil. Acta Botanica Brasilica, v. 21, n. 4, p. 823-834, 2007. Disponível em: < http://dx.doi.org/10.1590/S0102-33062007000400007 >. Acesso em 05 fev. 2019.

BARROS, J. A escola dos annales e a crítica ao historicismo e ao positivismo. Territórios e Fronteiras, v. 3, n. 1, jan./jun. 2010. Disponível em: < http://dx.doi.org/10.22228/rt-f.v3i1.56>. Acesso em: 13 mar. 2018.

BRASIL. Decreto n. 535, de 20 de maio de 1992. Cria a Reserva Extrativista do Extremo Norte do Estado do Tocantins. Brasília, DF: 1992. Disponível : < http://www2.camara.leg.br/legin/fed/decret/1992/decreto-53520-maio-1992-343174-republicacao-1-pe.html >. Acesso em 20 nov. 2019.

GUATTARI, F.; ROLNIK, S. Micropolítica: cartografias do desejo. Petrópolis: Vozes, 2005.

HALBSBACH, M. A memória coletiva. São Paulo, SP: Centauro, 2013.

HAMILTON, A. C. et al. The purposes and teaching of applied ethnobotany. Godalming, UK: WWF, 2003. Disponível em: < http://unesdoc.unesco.org/images/0014/001458/145847e.pdf >. Acesso em 18 mar. 2017.

HERRERO, B.; CARDAÑO, M. Ethnobotany in the folksongs of Castilla y León (Spain). Botanical Sciences, v. 93, n. 2, p. 1-12, 2015. Disponível em: < http://dx.doi.org/10.17129/botsci.88 >. Acesso em 05 fev. 2019.

KOGEYAMA, C. As diferentes concepções de educação ambiental presentes no programa nascentes verdes rios vivos do instituto de pesquisas ecológicas. 2018. 156f. Dissertação (Mestrado em Ciências) Universidade de São Paulo, 2018. Disponível em: < https://www.teses.usp.br/teses/disponiveis/100/100134/tde29012018-101503/publico/CintiaKogeyama.pdf >. Acesso em 05 fev. 2019.

MAIA, M.; ROCHA, D. A fenomenologia na pesquisa em educação: um olhar sobre a etnometodologia e a etnopesquisa crítica. Atos de Pesquisa em Educação, Blumenau, v. 11, n. 3, 2016. Disponível em: < http://dx.doi.org/10.7867/1809-0354.2016v11n3p718-736 >. Acesso em 05 fev. 2019.

MANACORDA, M. História da educação: da antiguidade aos nossos dias. São Paulo: Cortez, 2006.

MERLEAU-PONTY, M. Fenomenologia da percepção. São Paulo: Martins Fontes, 1999. 
MOURÃO, I. et al. Aspectos socioambientais e de saúde das quebradeiras de coco babaçu na microrregião do Bico do Papagaio, Tocantins, Brasil. Ambiente e Água, Taubaté, v. 11, suplemento, 2016. Disponível em: < http://dx.doi.org/10.4136/ambi-agua.1920 >. Acesso em 05 fev. 2019.

NASCIMENTO, A. et al. Comunidade de palmeiras no território indígena Krahô, Tocantins, Brasil: biodiversidade e aspectos etnobotânicos. Interciencia, v. 34, n. 3, mar. 2009. Disponível em: < http://dx.doi.org/10.5380/rf.v40i1.17112 > Acesso em 05 fev. 2019.

NASCIMENTO, J. Tocantins: história e geografia. Goiânia: Bandeirante, 2011.

NOVAES, J.; ARAÚJO, H. Cartografia social na região ecológica do Babaçu: estratégias de quebradeiras de coco e processos sociais atinentes aos babaçuais. R. Pol. Públ., São Luís, n. esp., p. 179-188, nov. 2016. Disponível em: < http://dx.doi.org/10.18764/2178-2865.v20nEp179-188 >. Acesso em 05 fev. 2019.

ODA, W. Animais que peidam: trabalhando a biodiversidade entre os Baniwa e os Koripako, Amazonas, Brasil. ENCONTRO NACIONAL DE ENSINO DE BIOLOGIA, VII, Anais... [no prelo]. Belém, UFPA, 2018.

OLIVEIRA, F. et al. Avanços nas pesquisas etnobotânicas no Brasil. Acta bot. bras., v. 23, n. 2, p. 590-605, 2009. Disponível em : < http://dx.doi.org/10.1590/S0102-33062009000200031 >. Acesso em 05 fev. 2019.

PORRO, N. et al. Traditional communities in the brazilian amazonia and the emergence of new political identities: the struggle of the quebradeiras de coco babaçu - babassu breaker women. Journal of Cultural Geography, v. 28, n. 1, p. 126-143, feb. 2011. Disponível em: < https://doi.org/10.1080/08873631.2011.548487 $>$. Acesso em 05 fev. 2019.

PROTÁSIO, T. et al. Babassu nut residues: potential for bioenergy use in the North and Northeast of Brazil. SpringerPlus, v. 3, n. 124, 2014. Disponível em: < https://doi.org/10.1186/2193-1801-3-124 >. Acesso em 21 nov. 2018.

RODRIGUES, E.; CARLINI, E. Ritual use of plants with possible action on the central nervous system by the krahô indians, brazil. Phytotherapy research, v. 19, p. 129-135, 2005. Disponível em: < https://doi.org/10.1002/ptr.1636 >. Acesso em 05 fev. 2019.

SILVA, L. Biomas presentes no Estado do Tocantins. Brasília: Câmara dos Deputados, 2007.

VÁZQUEZ-ALONSO, M. et al. Etnobotánica de la cultura teotihuacana. Botanical Sciences, v. 92, n. 4, p. 563-574, 2014. Disponível em: < http://dx.doi.org/10.17129/botsci.118 >. Acesso em 05 fev. 2019.

VÁSQUEZ, S. et al. Etnobotânica de plantas medicinais em comunidades ribeirinhas do município de Manacapuru, Amazonas, Brasil. Acta Amazonica, v. 44, n. 4, p. 457-472, 2014. Disponível em: < http://dx.doi.org/10.1590/1809-4392201400423 >. Acesso em 05 fev. 2019.

VIU, A. et al. Etnobotânica: uma questão de gênero? Revista Brasileira de Agroecologia, v. 5, n . 01, p. 138147, 2010. Disponível em: < $\quad$ http://revistas.abaagroecologia.org.br/index.php/rbagroecologia/article/view/9525/6659 >. Acesso em 05 fev. 2018. 